\title{
Post-traumatic dissecting aneurysms of bilateral cervical carotid arteries with delayed complications
}

\author{
Avinash Kumar Kanodia, Meena Gupta*, Kiran Bala*, Sunil Kumar, Suman Kushwaha*, \\ Sanjay Pandey*
}

Departments of Neuroradiology and *Neurology, Institute of Human Behaviour and Allied Sciences, Dilshad Garden, Delhi - 110095, India

Carotid dissection is an uncommon complication of trauma. They can present with immediate or delayed complications. We describe the case of a young patient with bilateral carotid dissections and acute infarcts. Brief review of literature and treatment options are discussed.

Key words: Dissection, trauma, infarct

Dissection of cervical internal carotid arteries (ICA) is an unusual complication of trauma. Bilateral dissections and dissecting aneurysms are extremely rare. ${ }^{[1]}$ The patient may be symptomatic immediately after trauma, or less commonly, after a gap of weeks, months or years. ${ }^{[2]}$

A 20-year-old man developed sudden-onset right hemiparesis and aphasia, minutes after a gymnasium workout. MRI revealed multiple acute infarcts in left frontoparietal and small infarcts in right frontal lobe [Figure 1]. Patient improved within 5 days of the acute event. He gave history of road traffic accident just over a year back, in which he had suffered head injury and was unconscious for 7-8 hours. Since then, he had been asymptomatic. Digital subtraction angiography (DSA) revealed dissecting aneurysms in bilateral cervical ICAs, just proximal to the skull base. On right side, there was no stasis in the aneurysm and no narrowing of the vascular lumen [Figure 2]. On left side, the aneurysm neck was narrow and there was considerable stasis of the contrast, with narrowing of the lumen of the vessel by $30 \%$ [Figure 3].

Arterial dissection may lead to stenosis, vascular occlusion or sometimes, pseudoanerysm formation. Usual etiologies include trauma, arteritis, iatrogenic (including post-surgical), spontaneous and infections. The cervical ICA just proximal to the skull base is a site of predisposition in trauma. Most commonly,
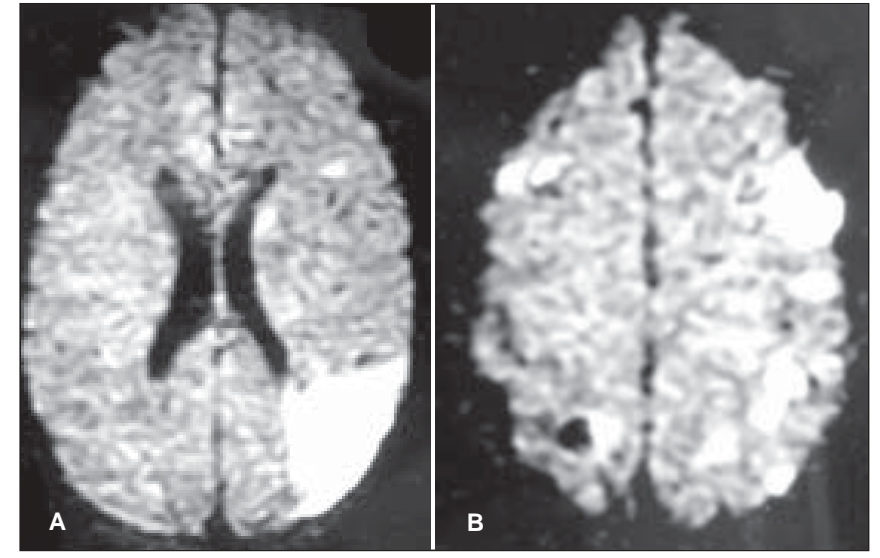

Figure 1: Shows diffusion weighted MRI axial images (A) and (B)

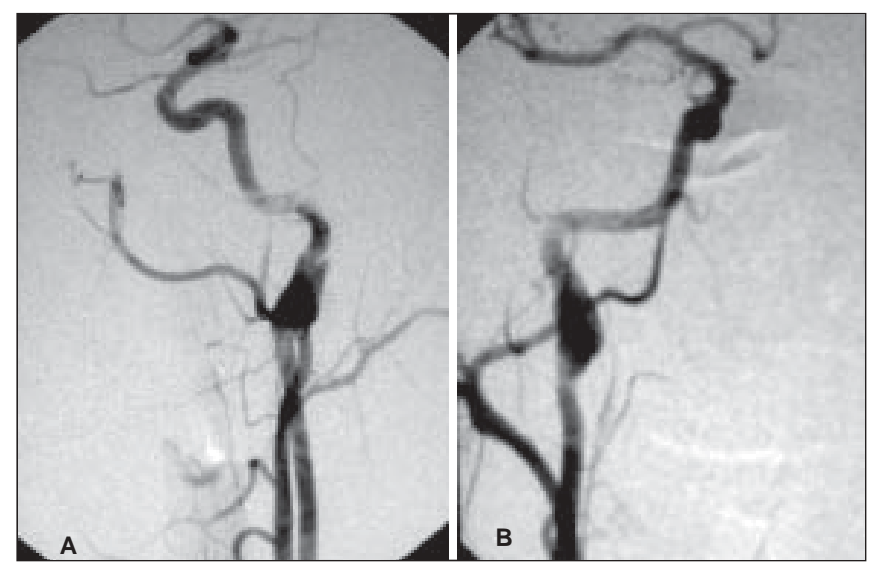

Figure 2: Lateral (A) and AP (B) views of the right cervical carotid showing dissecting aneurysm formation at distal cervical ICA

they present as neurological deficits or transient ischaemic attacks (TLA). Other presentations include neck pain, compression of cranial nerves, pulsatile neck masses, rupture and Horner's 

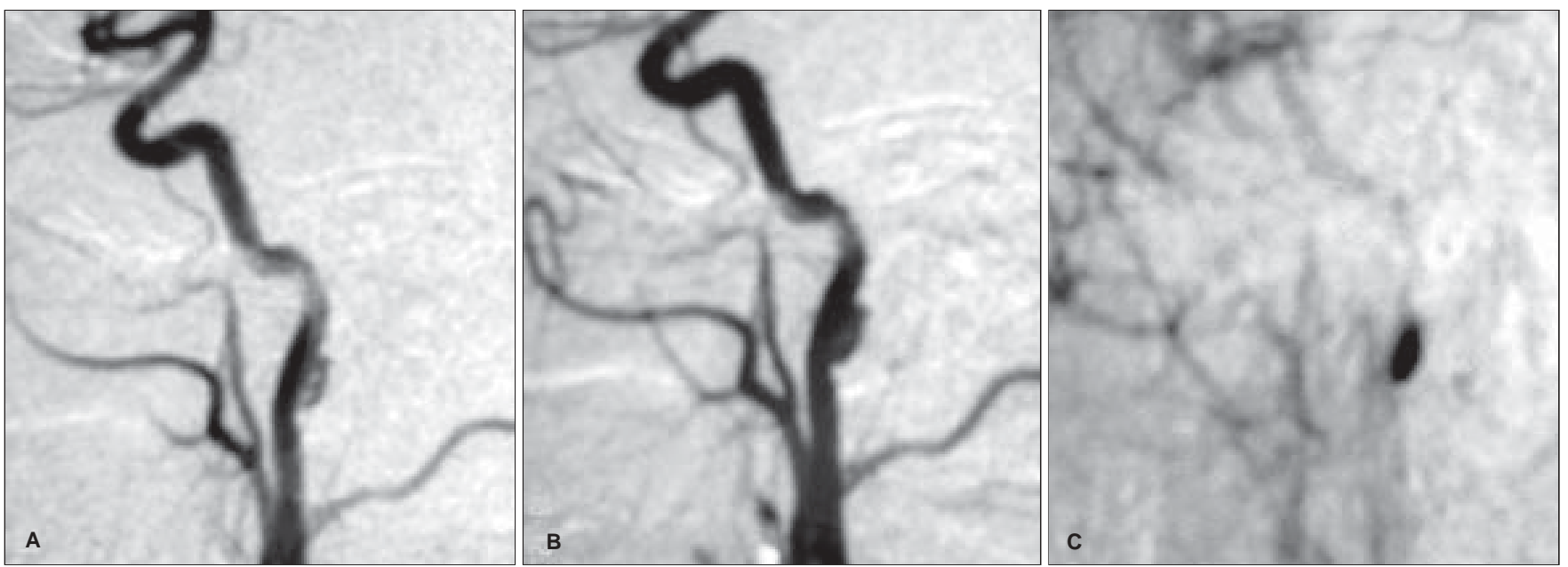

Figure 3: $(A, B, C)$ Lateral views of left cervical carotid showing dissecting aneurysm in distal carotid ICA, with stasis and mild narrowing of lumen.

syndrome. Sometimes, they present later with ischaemic symptoms varying from weeks to years; upto 6 year interval has been reported, ${ }^{[2]}$ with devastating consequences. ${ }^{[3]}$ The late embolic event may be precipitated by minor trauma or a sudden neck movement, that might dislodge a thrombus. In the present case, the symptoms occurred immediately after the patient had a gymnasium workout. Although the possibility of dissection at the time of gymnasium workout is present, it is less likely, as the patient did not experience any pain at that time.

The diagnosis is usually confirmed by CT or MR angiography, although DSA is the gold standard, particularly for the haemodynamic assessment. In the present case, there was considerable stasis of contrast on the symptomatic left side, which predisposes to thromboembolism.

Antiplatelet and/or anticoagulant therapy has been advocated as effective treatment in carotid dissections, ${ }^{[4]}$ but healing of pseudoaneurysms is quite rare with medical treatment alone. ${ }^{[3]}$ Surgery is hampered by difficult approach to distal cervical ICA. ${ }^{[5]}$ Covered stent grafting is increasingly being performed for treating such patients with good results, ${ }^{[6]}$ although the long-term patency rate of covered stents is not known.
In conclusion, bilateral dissecting aneurysms of distal cervical ICAs are extremely rare, and may have late complications. Early detection by keeping a high index of suspicion is required to prevent delayed complications, which could be devastating.

\section{References}

1. Chomel A, Vernet M, Lile A, Messant I, Combes JC, Freysz M. Traumatic bilateral dissections of the internal carotid artery: an infrequent diagnosis not to be missed. J Neurosurg Anesthesiol 2002;14:309-12.

2. Wurm G, Loffler W, Wegenschimmel W, Fischer J. Traumatic injury of the internal carotid artery in the extracranial segment. Description of a severe late complication. Chirurg- 1995;66:916-9.

3. Pretre R, Kursteiner K, Reverdin A, Faidutti B. Blunt carotid artery injury: devastating consequences of undetected pseudoaneurysm. J Trauma: 1995;39:1012-4.

4. Gelal FM, Kitis O, Calli C, Yunten N, Vidinli BD, Uyour M. Craniocervical artery dissection: diagnosis and follow-up with MR imaging and MR angiography. Med Sci Monit- 2004;10:MT109-16.

5. Sundt TM .Jr, Pearson BW, Piepgras DG, Houser OW, Mokri B. Surgical management of aneurysms of distal extracranial internal carotid artery. J Neurosurg 1986;64:169-82.

6. Layton KF, Kim YW, Hise JH. Use of covered stent grafts in the extracranial carotid artery: report of three patients with follow-up between 8 and 42 months. A.JNR 2004;25:1760-3.

Accepted on $04-12-2005$ 